\title{
Application of Multi-technique in Project Planning to Solve Time-cost Trade-off Problem
}

\author{
Asst. Prof. Dr. Mahmoud Abbas Mahmoud ${ }^{1}$, Dr. Luma Adnan AL-Kindi ${ }^{1}$, Haider Najy Hady ${ }^{1}$ \\ Production Engineering and Metallurgy Department/ Industrial Engineering Branch, University of Technology, \\ Baghdad, Iraq ${ }^{1}$
}

\begin{abstract}
One of the most important problems in project management is the time-cost trade-off problem (TCTP) that must be taken into consideration during project planning and control process through the use of suitable planning techniques. This study presented a model aims to solve (TCTP) using crashing as a traditional project planning technique and concurrency technique with activities partitioning in addition to new suggested technique that mixes between the two techniques and named as Concurrency-with Partitioning and Crashing Technique (CPCT). The model focuses on minimizing project time and cost and it is applied on an adopted case study. The results show that the suggested (CPCT) produces the best results for the two objectives compared to other applied techniques.
\end{abstract}

Keywords: project planning; time-cost trade-off problem; multi-technique; crashing technique; concurrency technique.

\section{INTRODUCTION}

Small and large-size projects have certain objectives to be achieved such as time, cost, resources, performance, scope, etc. that require planning, scheduling and control processes. These processes are considered to be important in the field of management and execution of projects, especially those that need coordination, large effort and long execution time. These processes could be applied through utilization of various project planning tools and techniques.

Project planning process involves four separate purposes:

- Cost and project duration determination as well as enabling the decision-making, in order to force the decision to go ahead with the project from the beginning.

- Required resources level determination.

- Work assigning and project progress monitoring assisting.

- Helping in estimating the effect of any altering to the project [1].

After completing planning process on work activities, scheduling process is lunched in order to determine the duration for these activities. This process includes representation of sequences and phases of individual activities required to complete work execution [2].

Time-Cost Trade-off Problem (TCTP) occurs when the change in project execution time could effect on the project cost; that is, decreasing in project execution time leads to an increasing in the total project cost and vise versa [3]. This problem could be solved through utilizing some of project management tools and techniques, following are a number of them:

Gantt chart is the method that is used to show progression of the project graphically. Project management could be performed simply if it is observed as small manageable entities where the dependencies are visibly cleared, parallel processes are detected, project progression can be tracking, and total processing durations are determined [4]. CPM/PERT are two closely related tools used to help project manager in performing the activities of developing a realistic schedule, and monitoring the progress of the project. PERT is an (Program Evaluation and Review Technique) and CPM is (Critical Path Method) [5].

Crashing technique can be defined as a particular type of compression techniques related with scheduling problems. This technique involves decreasing the total duration of project scheduling for an activity or activities after taking a number of alternatives to be analyzed for determining a way to get the maximum duration compression of schedule for the least added cost. There are a number of approaches for crashing a project schedule, including duration reduction of schedule activity as well as increasing resources assignment related with schedule activities [6].

Concurrent engineering is considered to be a systematic method that combines the primary idea of a project with its applied research, development, design, production, marketing, distribution, and sales. This method produces more effective and shorter design cycle while keeping product reliability and improving its quality through compression the schedule to permit simultaneous or overlap performing of many activities [7].

\section{LITERATURE REVIEW}

This section presents different studies published in the last years that employee different methods for solving the (TCTP):

Ding et al. (2010) [8]: they have presented a developed approach for solving the TCTP under imprecise conditions as a project scheduling problem using trapezoidal fuzzy numbers. The proposed model has estimated total 
completion cost within investment penalty cost and provided more choices for the decision maker. In order to expand the scale of calculation, multi-objective genetic algorithm (MOGA) has been applied.

Sahu, K. and Sahu, M. (2014) [9]: they have presented time management with optimum cost by means of crashing. An alternative approach has been given in order to get optimal cost and time in addition to minimum duration for the project with totally crashing in the critical path. The proposed method has been performed by directly minimizing the critical slope value hence minimizing the duration of the project. The results of this study have given such a preferable crashing values in addition to manage the time effectively. Al Haj, Rana A., and Sameh M. ElSayegh (2015) [10]: they have presented a model of nonlinear integer programming to solve the (TCTP) by taking into account the effect of total float-loss. In order to get a suitable solution for this problem, What'sBest solver package within Microsoft Excel has been used, and the computed total float-waste cost was combined based on the float-commodity method. The results from this study have focused on enabling project managers in examining the (TCTP) thus reaching certain project objectives.

\section{PROPOSED MODEL}

The proposed model presents an approach for solving TCTP through utilizing multiple project planning and control techniques. This model includes mathematical problem description using tools and project representation techniques to deal with activities and project data in an engineering manner, project planning and control techniques are applied for obtaining multi-objective results. Four stages are used to define this model.

Stage 1: defining planning and scheduling inputs required for the problem including:

- Number of activities (N).

- Activity symbol $\left(\mathrm{A}_{\mathrm{i}}\right.$, where $\mathrm{i}=(1,2,3, \ldots, \mathrm{N})$

- Activity Duration $\left(\mathrm{D}_{\mathrm{i}}\right)$.

- Activity Precedencies (APi).

- Activity Cost $\left(\mathrm{AC}_{\mathrm{i}}\right)$

- Indirect Cost per day $\left(\mathrm{IC}_{/ \mathrm{d}}\right)$.

- Direct Cost per day $\left(\mathrm{DC}_{/ \mathrm{d}}\right)$.

- Estimated project budget (EC).

- Project Duration (PD).

- Total Project Time (T).

- Total Project Cost (C).

Stage 2: Identifying project planning and control objectives, where in this stage two objectives are determined:

- Time: Project delivery within or less than the specified time.

- Cost: Project delivery within or less than the estimated budget.

Stage 3: Inputs representation using Gantt Chart and CPM network, where in this stage project activities are represented according to Fig. 1. The following abbreviations could be defined as follows:
Indirect activity Cost (IC).

- Direct and Indirect Activity Cost $\left(\mathrm{DI}_{\mathrm{i}}\right)$.

- Total Project Cost (TC).

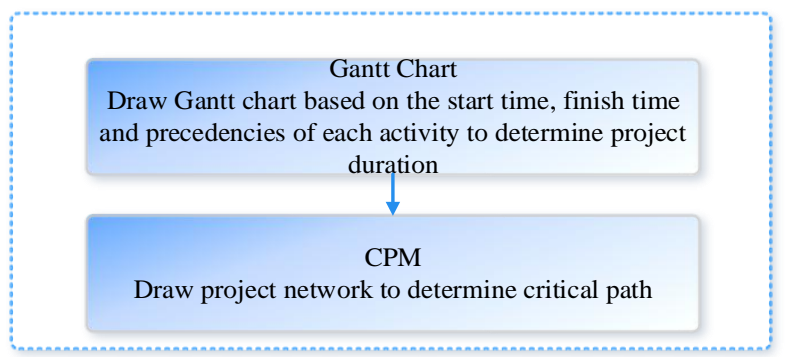

Fig. 1. Representation of project duration by Gantt chart and CPM

Stage 4: Applying multi-technique as project planning alternatives, where in this model, some of these techniques are applied; these are:

\section{A. Crashing Technique}

The main steps of crashing technique can be described as shown in Fig. 2. The following abbreviations could be defined as follows:

- Normal Time (NT).

- Crashing Time (CT).

- Normal Cost (NC).

- Crashing Cost (CC).

- Cost Slope (CS).

- Indirect Project Cost (IPC).

- Project Duration (PD).

- Project Direct Cost (DC).

- Crashing Cost Slope (Ccslop).

- Crashing Cost Slope Cumulative (CCp).

- $\Delta \mathrm{T}$ of The New Activity $(\Delta \mathrm{Tn})$.

- CS of The New Activity (CSn).

B. Concurrency Technique with Partitioning (CP)

This technique is applied in project planning process with the aid of Gantt chart; where the total project execution time is reduced through planning and execution of some of project activities concurrently after partitioning some of them if they need without affecting on the rest of the activities in terms of their precedencies and execution time. These activities are also executed within their defined time. Fig. 3 describes the main steps that are applied in this technique.

C. Concurrency-Partitioning and Crashing Technique (CPCT)

The researcher suggests a new approach that mixes between two techniques, concurrency and crashing after partitioning some of project activities. This approach is named as Concurrency-Partitioning and Crashing technique (CPC). The purpose of this combination is to be considered as an addition alternative that could be compared with other applied techniques in order to facilitate the process of decision-making. Fig. 4 shows the main steps of applying this approach. 


\section{International Advanced Research Journal in Science, Engineering and Technology \\ ISO 3297:2007 Certified}

Vol. 3, Issue 9, September 2016

\section{IV.MODEL IMPLEMENTATION} An industrial construction project is taken as a case study. days; the direct cost was $4460 \$$, and the indirect cost was The project involves construction of steel warehouse to $80 \$$ per day. Normal and crash durations in addition to protect large equipment used for engine production in heavy industry.

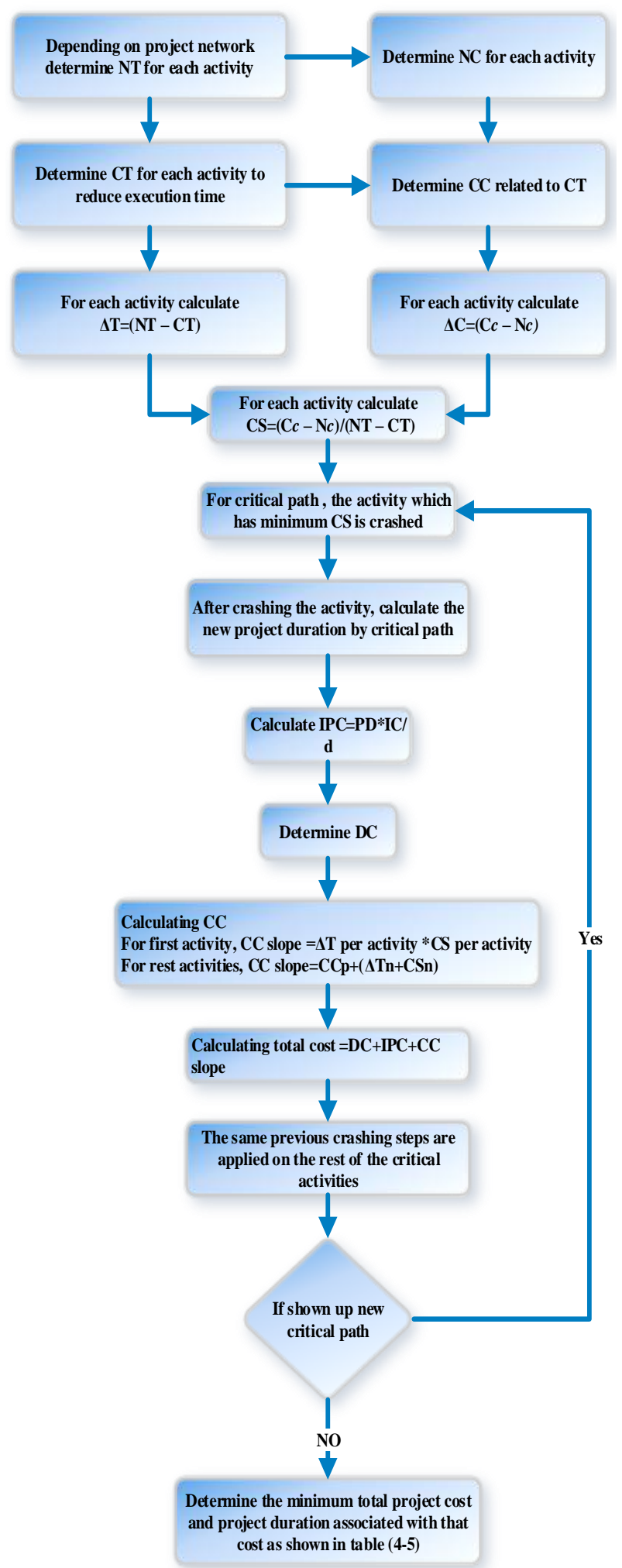

Fig. 2. Flowchart of crashing technique steps
After drawing project network and Gantt Chart depicted in Fig. 5 and Fig. 6 respectively; project duration was 184 are illustrated in table I.

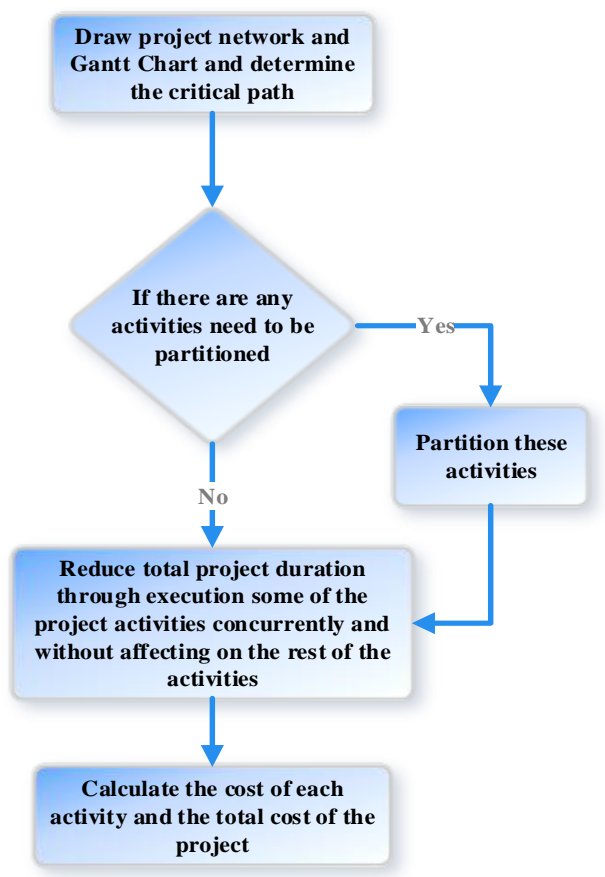

Fig.3. Flowchart of (CP) technique

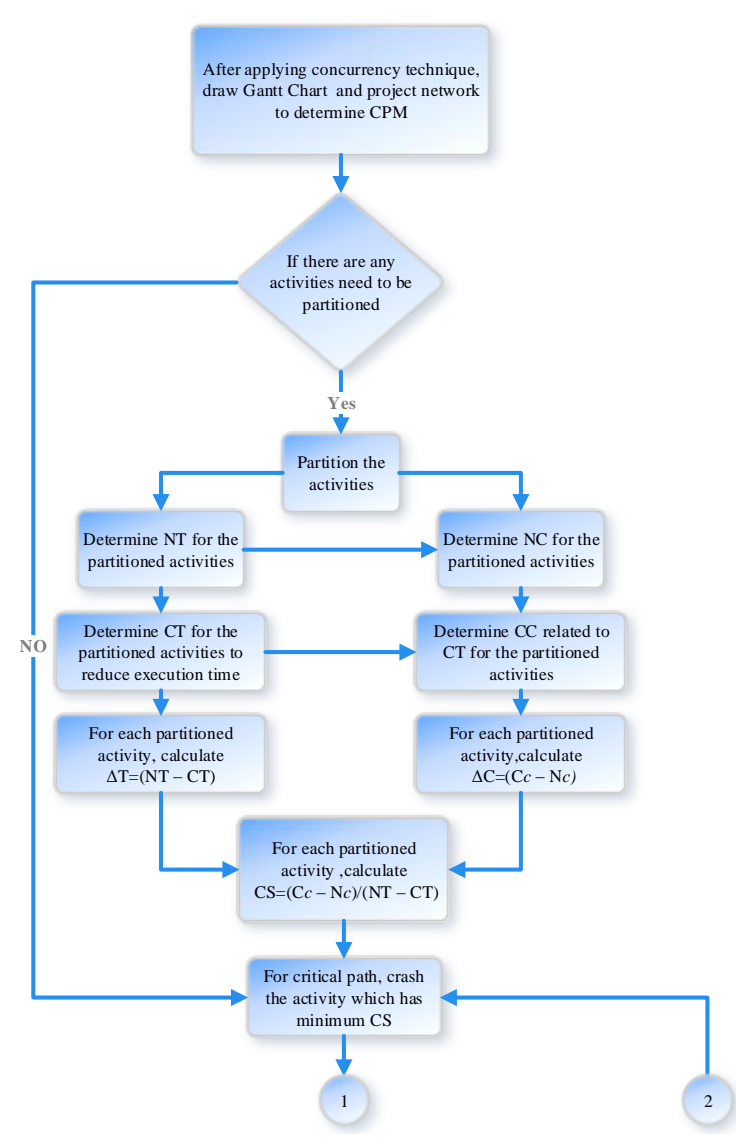




\section{International Advanced Research Journal in Science, Engineering and Technology}

\section{ISO 3297:2007 Certified}

Vol. 3, Issue 9, September 2016

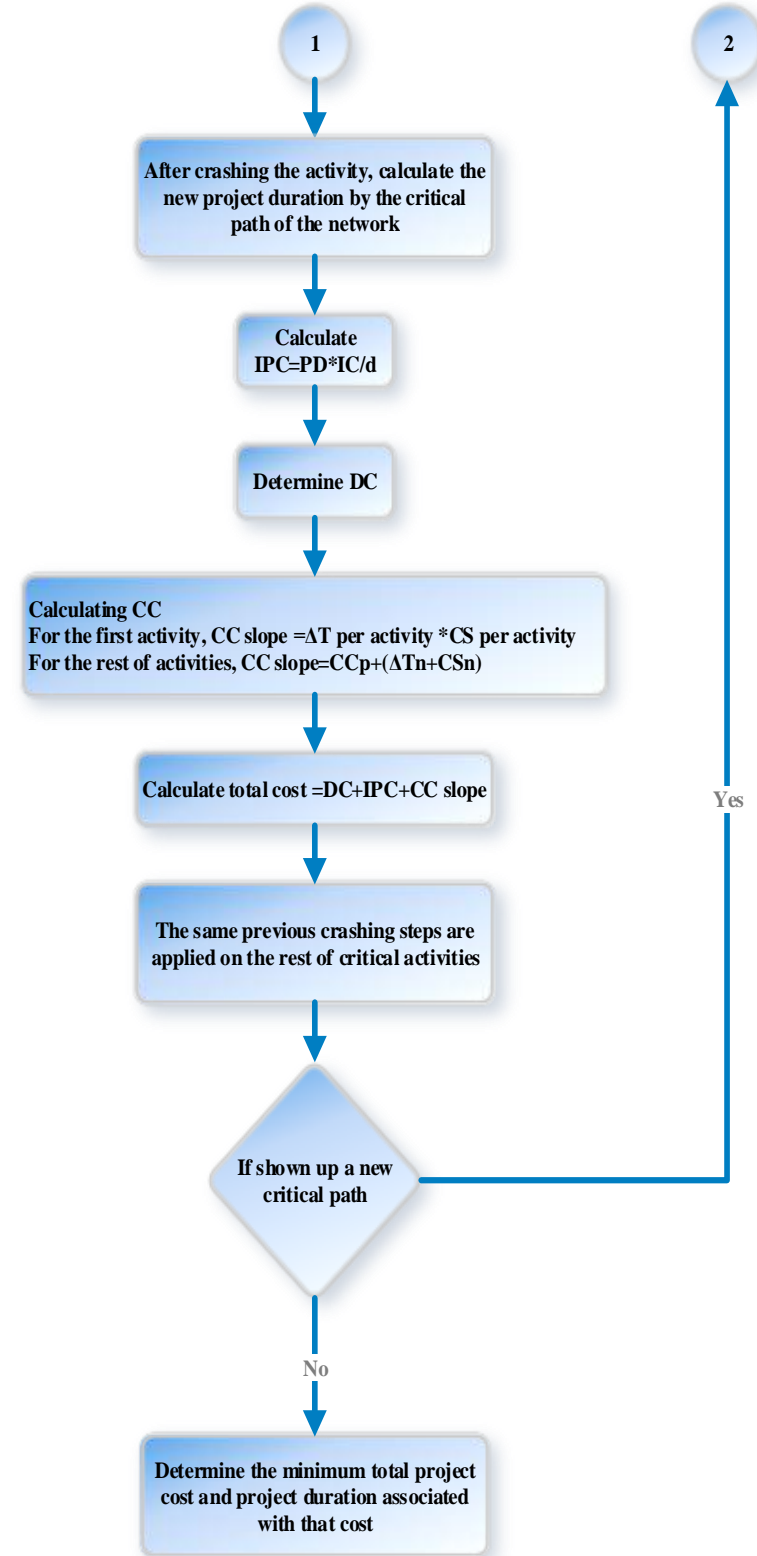

Fig. 4. Flowchart of the suggested approach (CPCT)

Following is a list of project activities and their corresponding symbols:
A Preparations
B Order machine
C Deliver machine
D Order building materials
E Preparatory works on site
F Conveyance of bulldozers
G Delivery of gravel and cement
$\mathrm{H}$ Delivery of mount structure
I Delivery of prefabricated steel structure
J Groundwork
$\mathrm{K}$ Foundation for the depot
$\mathrm{L}$ Placing the mount for the machine
M Placing the machine on the mount
$\mathrm{N}$ Assembling the building structure
$\mathrm{O}$ Finishing works, project delivery

TABLE I: Information of the Case Study

\begin{tabular}{|c|c|c|c|c|c|c|}
\hline $\mathbf{A}_{\mathbf{i}}$ & $\mathbf{A} \mathbf{P}_{\mathbf{i}}$ & $\begin{array}{l}\text { NT } \\
\text { (day) }\end{array}$ & $\begin{array}{l}\mathbf{N C} \\
(\$)\end{array}$ & $\begin{array}{c}\text { CT } \\
\text { (day) }\end{array}$ & $\begin{array}{l}\text { CC } \\
(\$)\end{array}$ & CS \\
\hline A & ----- & 30 & 100 & 20 & 200 & 10 \\
\hline B & $\mathrm{A}$ & 20 & 30 & 15 & 50 & 4 \\
\hline $\mathrm{C}$ & $\mathrm{B}, \mathrm{E}$ & 30 & 400 & 20 & 600 & 20 \\
\hline $\mathrm{D}$ & $\mathrm{A}$ & 10 & 30 & 6 & 50 & 5 \\
\hline $\mathrm{E}$ & A & 14 & 150 & 10 & 230 & 20 \\
\hline $\mathrm{F}$ & $\mathrm{A}$ & 30 & 120 & 25 & 195 & 15 \\
\hline $\mathrm{G}$ & $\mathrm{D}, \mathrm{E}$ & 20 & 90 & 12 & 154 & 8 \\
\hline $\mathrm{H}$ & $\mathrm{D}, \mathrm{E}$ & 80 & 160 & 50 & 370 & 7 \\
\hline I & $\mathrm{D}, \mathrm{E}$ & 90 & 280 & 50 & 520 & 6 \\
\hline $\mathrm{J}$ & $\mathrm{F}, \mathrm{E}$ & 10 & 600 & 5 & 720 & 24 \\
\hline $\mathrm{K}$ & $\mathrm{G}, \mathrm{J}$ & 30 & 1200 & 25 & 1500 & 60 \\
\hline $\mathrm{L}$ & $\mathrm{K}, \mathrm{H}$ & 20 & 150 & 15 & 350 & 40 \\
\hline $\bar{M}$ & $\mathrm{C}, \mathrm{L}$ & 5 & 200 & 5 & 200 & 0 \\
\hline $\mathrm{N}$ & M, I & 20 & 800 & 12 & 1200 & 50 \\
\hline $\mathrm{O}$ & $\mathrm{N}$ & 15 & 150 & 10 & 210 & 12 \\
\hline
\end{tabular}

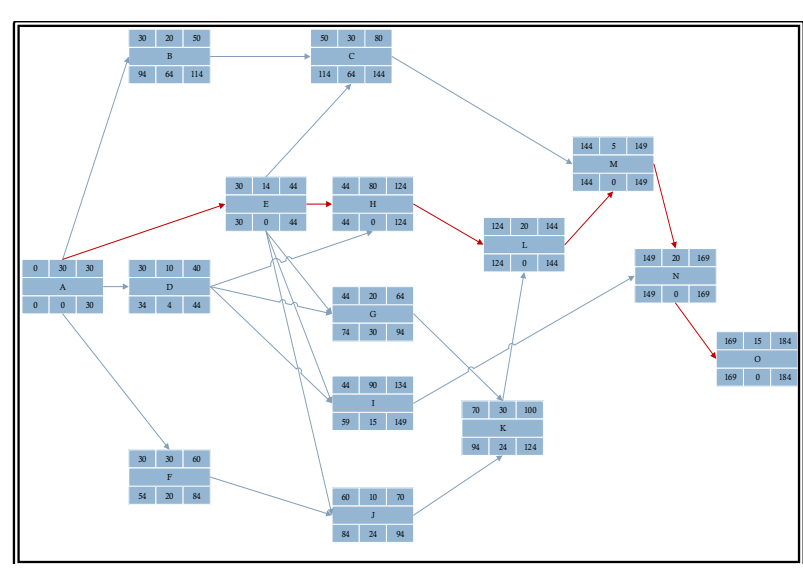

Fig. 5. Planned project network

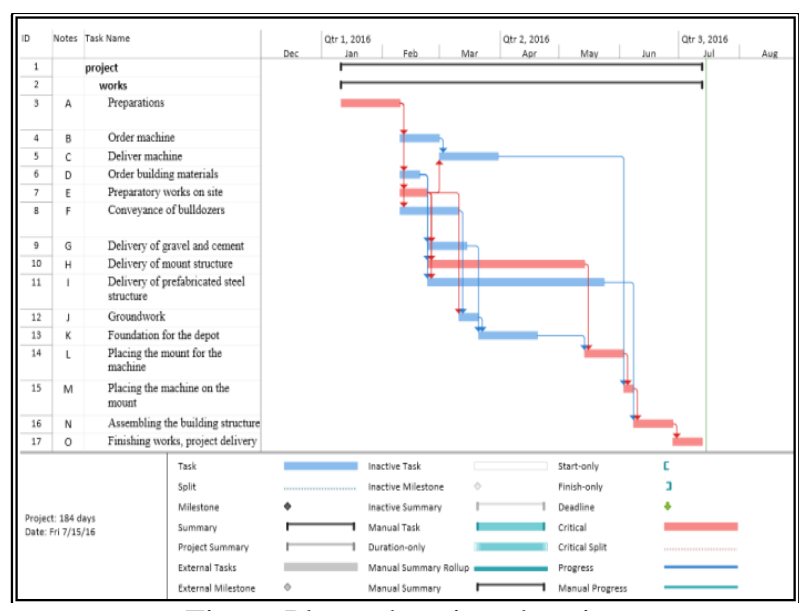

Fig. 6. Planned project duration

In this case study, three techniques have been applied. The first one was the crashing technique, in which the critical activities have been crashed according to the availability of crashing information in table I and as shown in table II, where the resulted duration was 122 days while the cost was $15,769 \$$. 
Vol. 3, Issue 9, September 2016

The second was the concurrency technique with partitioning (CP), in which, activity $\mathrm{A}$ has been partitioned into two parts; $\mathrm{A}$ and $\mathrm{A} 1$, where activity $\mathrm{F}$ has been made to be executed concurrently with the second part A1. Table III illustrates the partitioning activity and application of concurrency technique. Gantt Chart and project network are illustrated in Fig. 7 and Fig. 8 respectively. The chart describes overlapping process among activities while the network is used to determine project execution time that was 180 days in addition to the project cost that was $18860 \$$.

The third technique was the suggested mixed approach (CPCT). Depending on (CP) results and its network and information available in table III; the activities have been crashed as demonstrated in table IV.

TABLE II: Project activities after crashing

\begin{tabular}{|c|c|c|c|c|c|c|c|c|}
\hline 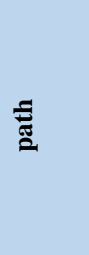 & 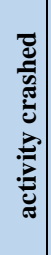 & $\overline{8}$ & 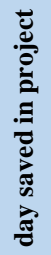 & 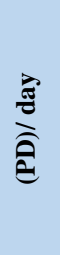 & 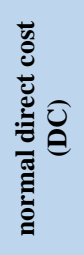 & 己े & ঠી & $\frac{\bar{t}}{\frac{0}{0}}$ \\
\hline CPM1 & - & -- & -- & 184 & 4460 & 0 & 14720 & 19180 \\
\hline CPM1 & $\mathrm{H}$ & 30 & 15 & 169 & 4460 & 210 & 13520 & 18190 \\
\hline CPM2 & I & 40 & 9 & 160 & 4460 & 450 & 12800 & 17710 \\
\hline CPM3 & A & 10 & 10 & 150 & 4460 & 550 & 12000 & 17010 \\
\hline CPM3 & $\mathrm{O}$ & 5 & 5 & 145 & 4460 & 610 & 11600 & 16670 \\
\hline CPM3 & F & 5 & 5 & 140 & 4460 & 685 & 11200 & 16345 \\
\hline CPM3 & $\mathrm{J}$ & 5 & 1 & 139 & 4460 & 805 & 11120 & 16385 \\
\hline CPM4 & G & 8 & 0 & 139 & 4460 & 869 & 11120 & 16449 \\
\hline CPM1 & $\mathrm{E}$ & 4 & 4 & 135 & 4460 & 949 & 10800 & 16209 \\
\hline CPM1 & $\mathrm{L}$ & 5 & 5 & 130 & 4460 & 1149 & 10400 & 16009 \\
\hline CPM1 & $\mathrm{N}$ & 8 & 8 & 122 & 4460 & 1549 & 9760 & 15769 \\
\hline CPM3 & $\mathrm{K}$ & 5 & 0 & 122 & 4460 & 1849 & 9760 & 16069 \\
\hline
\end{tabular}

TABLE III: Project activities after application of (CP) technique

\begin{tabular}{|c|c|c|c|c|c|c|}
\hline $\mathbf{A}_{\mathbf{i}}$ & $\mathbf{A P}_{\mathbf{i}}$ & $\mathbf{N T}$ (day) & $\mathbf{N C} \mathbf{( \$ )}$ & $\mathbf{C T}$ (day) & $\mathbf{C C} \mathbf{( \$ )}$ & $\mathbf{C S}$ \\
\hline $\mathrm{A}$ & ----- & 25 & 83 & 17 & 160 & 9.63 \\
\hline $\mathrm{A} 1$ & $\mathrm{~A}$ & 5 & 17 & 3 & 40 & 11.5 \\
\hline $\mathrm{B}$ & $\mathrm{A} 1$ & 20 & 30 & 15 & 50 & 4 \\
\hline $\mathrm{C}$ & $\mathrm{B}, \mathrm{E}$ & 30 & 400 & 20 & 600 & 20 \\
\hline $\mathrm{D}$ & $\mathrm{A} 1$ & 10 & 30 & 6 & 50 & 5 \\
\hline $\mathrm{E}$ & $\mathrm{A}$ & 14 & 150 & 10 & 230 & 20 \\
\hline $\mathrm{F}$ & $\mathrm{A}$ & 30 & 120 & 25 & 195 & 15 \\
\hline $\mathrm{G}$ & $\mathrm{D}, \mathrm{E}$ & 20 & 90 & 12 & 154 & 8 \\
\hline $\mathrm{H}$ & $\mathrm{D}, \mathrm{E}$ & 80 & 160 & 50 & 370 & 7 \\
\hline $\mathrm{I}$ & $\mathrm{D}, \mathrm{E}$ & 90 & 280 & 50 & 520 & 6 \\
\hline $\mathrm{J}$ & $\mathrm{F}, \mathrm{E}$ & 10 & 600 & 5 & 720 & 24 \\
\hline $\mathrm{K}$ & $\mathrm{G}, \mathrm{J}$ & 30 & 1200 & 25 & 1500 & 60 \\
\hline $\mathrm{L}$ & $\mathrm{K}, \mathrm{H}$ & 20 & 150 & 15 & 350 & 40 \\
\hline $\mathrm{M}$ & $\mathrm{C}, \mathrm{L}$ & 5 & 200 & 5 & 200 & 0 \\
\hline $\mathrm{N}$ & $\mathrm{M}, \mathrm{I}$ & 20 & 800 & 12 & 1200 & 50 \\
\hline $\mathrm{O}$ & $\mathrm{N}$ & 15 & 150 & 10 & 210 & 12 \\
\hline
\end{tabular}

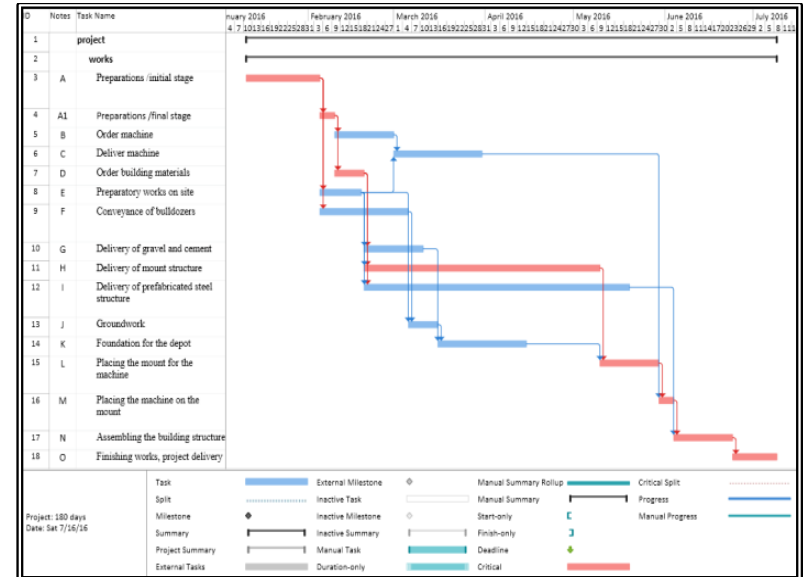

Fig. 7. Gantt Chart of (CP) technique

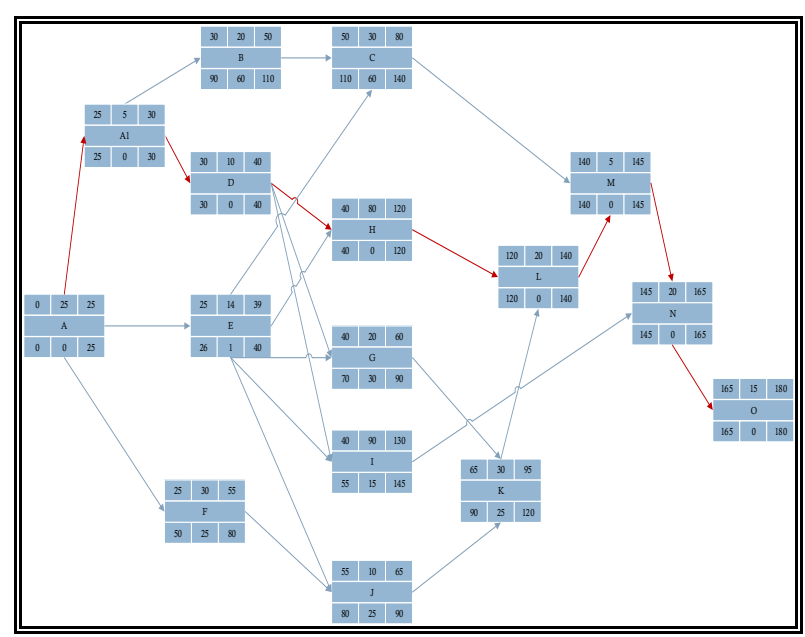

Fig. 8. Project Network of (CP) technique

TABLE IV: Project activities after crashing for (CPCT)

\begin{tabular}{|c|c|c|c|c|c|c|c|c|}
\hline 气ี & 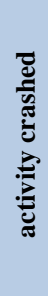 & E & 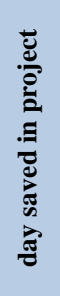 & 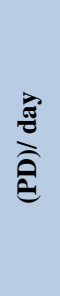 & 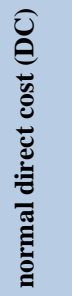 & $\widehat{己}$ & ঠิ & 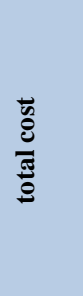 \\
\hline CPM1 & -- & -- & -- & 180 & 4460 & 0 & 14400 & 18860 \\
\hline CPM1 & D & 4 & 1 & 179 & 4460 & 20 & 14320 & 18800 \\
\hline CPM2 & $\mathrm{H}$ & 30 & 15 & 164 & 4460 & 230 & 13120 & 17810 \\
\hline CPM3 & I & 40 & 9 & 155 & 4460 & 470 & 12400 & 17330 \\
\hline$\overline{\text { CPM4 }}$ & $\bar{A}$ & 8 & 8 & 147 & 4460 & 547 & 11760 & 16767 \\
\hline CPM4 & $\mathrm{O}$ & 5 & 5 & 142 & 4460 & 607 & 11360 & 16427 \\
\hline CPM4 & $F$ & 5 & 5 & 137 & 4460 & 682 & 10960 & 16102 \\
\hline CPM4 & $\mathrm{J}$ & 5 & 1 & 136 & 4460 & 802 & 10880 & 16142 \\
\hline$\overline{\text { CPM5 }}$ & G & 8 & 0 & 136 & 4460 & 866 & 10880 & 16206 \\
\hline CPM2 & $\mathrm{E}$ & 4 & 3 & 133 & 4460 & 946 & 10640 & 16046 \\
\hline CPM1 & A1 & 2 & 1 & 132 & 4460 & 969 & 10560 & 15989 \\
\hline CPM2 & $\mathrm{L}$ & 5 & 5 & 127 & 4460 & 1169 & 10160 & 15789 \\
\hline CPM2 & $\mathrm{N}$ & 8 & 8 & 119 & 4460 & 1569 & 9520 & 15549 \\
\hline CPM4 & K & 5 & 5 & 119 & 4460 & 1869 & 9520 & 15849 \\
\hline
\end{tabular}


Vol. 3, Issue 9, September 2016

\section{DISCUSSION AND EVALUATION}

The suggested (CPCT) results were 119 days for project duration and 15549 \$ for project cost. Accordingly, this approach presented minimum time and cost compared with the other two techniques in addition to (CPM) network of the original plan, so that, the suggested (CPCT) approach could be considered the most effective technique in solving (TCTP). Table $\mathrm{V}$ demonstrates the final comparison between the applied techniques.

TABLE V: Comparison among the applied techniques

\begin{tabular}{|c|c|c|}
\hline Technique & $\begin{array}{l}\text { Time } \\
\text { (days) }\end{array}$ & Cost $\mathbf{( \$ )}$ \\
\hline CPM & 184 & 19180 \\
\hline Crashing & 122 & 15769 \\
\hline CP & 180 & 18860 \\
\hline CPCT & 119 & 15549 \\
\hline
\end{tabular}

\section{CONCLUSIONS}

The model has been suggested to solve time-cost trade-off problem and it could be applied to help project management in planning and scheduling processes for different types of projects.

Three techniques have been applied as alternatives these are crashing, concurrency technique with partitioning, and a new suggested approach combines between concurrency technique with partitioning and crashing technique which is named as concurrency-partitioning and crashing technique. The results have shown that the suggested mixed approach was the best one among other techniques.

\section{REFERENCES}

[1] S. Nigel, C. Stuart, and J. Robert, Operations management, 6th ed., Pearson education, 2010.

[2] H. C. John, and M. P. Brian, An Introduction to the Management Principles of Scheduling, A report presented to the Virginia Department of Transportation and the VDOT-VT Partnership for Project Scheduling Advisory Board, 2005.

[3] B. Hooshyar, A. Tahmani, and M. Shenasa, "A Genetic Algorithm to Time-Cost Trade off in project scheduling," In 2008 IEEE Congress on Evolutionary Computation (IEEE World Congress on Computational Intelligence), pp. 3081-3086. IEEE, 2008.

[4] W. Abimbola, Fundamentals of Construction Management, Ventures Publishing ApS, 2013.

[5] H. S. Frederick, and L. J. Gerald, Introduction to Operations Research, 7th ed., McGraw Hill. New York, 2001.

[6] D. R. William, A guide to the project management body of knowledge, PMI Publications ,1996.

[7] A. B. Robert, G. A. Norman, and C. P. Thomas, Planning, performing, and controlling projects: principles and applications, Prentice Hall, 2000.

[8] C. H. Ding, S. Fujimura, X. Wei, and W. Wei. "Time-cost trade-off problem under uncertainty incorporating multi-objective genetic algorithm and fuzzy sets theory," In Industrial Engineering and Engineering Management (IE\&EM), 2010 IEEE 17Th International Conference on, pp. 290-294. IEEE, 2010.

[9] S. Komesh and S. Meenu, "Cost \& Time and Also Minimum Project Duration Using Alternative Method," International Review of Applied Engineering Research, pp. 403-412, 2014.
[10] Al Haj A. Rana, and El-Sayegh M. Sameh, "Time-Cost Optimization Model Considering Float-Consumption Impact," Journal of Construction Engineering and Management 141, no. 5: p.04015001, 2015. 